\title{
Teaching mode action research of multidimensional interactive college English
}

\author{
Ming Yang ${ }^{1, a}$ \\ ${ }^{1}$ Department of Foreign Languages, Hanjiang Normal University, Shiyan city, Hubei Province, China \\ a2914951@qq.com
}

Keywords: College English, The multidimensional interaction, Interactive teaching, Teaching model

\begin{abstract}
College English with the English teaching reform arises at the historic moment and more mature, but because of the teaching idea obsolete, the number of students, basic English, and many other factors, the teaching effect has been very not ideal, this paper on the basis of the existing cognitive in the educational world research and explore multi-dimensional English interactive teaching strategies and principles, in order to further understanding the law of the multi-dimensional interactive teaching, scientific design the teaching plan, in order to increase the effectiveness of English teaching.
\end{abstract}

\section{Introduction}

The rapid development of economy makes us showed a trend of diversification of the demand for foreign language talents, at the same time put forward higher requirements of college English teaching. "College English curriculum requirements issued by the ministry of education in 2004", "the curriculum to fully embody the personalized, students with different starting point, low starting point is to take care of students, and to give the basic good students have a development space; both to ensure that during the whole university English language level will increase steadily, and to help students to learn, to meet their different requirements of professional development". Based on this, various universities in order to ensure continuous line of college English learning have increased the proportion of English [1]. However, due to us is still in the exploratory stage in teaching, most teachers are college English traditional teaching mode, teaching effect is not very ideal. Multi-dimensional interactive teaching as a kind of teaching mode of subjectivity, in improving the teaching atmosphere, improve teaching efficiency and promote the development of students good non-cognitive quality aspects of actual effect significantly, thus became one of the leading concept of teaching reform at present.

\section{The characteristics of the multi-dimensional interactive teaching}

The concept of multi-dimensional interactive teaching. Multi-dimensional interactive teaching as a kind of idea, has been generally recognized by the education community, and because it in promoting individual development and positive classroom vitality has been increasingly used in education practice [1]. Multi-dimensional interactive teaching emphasizes the active role of teaching both sides in the teaching process, with particular emphasis on the learner's subjectivity into full play, as a kind of teaching concept, it tries to change the teaching of the teachers' absolute dominance, create the teaching atmosphere of equality, cooperation between teachers and students, the teachers and students in such aspects as knowledge, thought, mental, emotional, mingled in the implementation of the teaching is learning.

The fundamental element of multi-dimensional interactive teaching mode. Multi-dimensional interactive teaching is to make a variety of factors to achieve interaction in the education system. Generally speaking, the education system is at least by the teaching environment, teaching subject, teaching process, teaching the results of four plates [2]. In the multi-dimensional interactive teaching, each plate in the teaching system is relatively independent and associated with each other, play to their respective functions, and constitute the basic elements of multi-dimensional interactive teaching mode. 
Teaching environment refers to the comprehensive teaching environment, such as social and school's education policy, society and environment of campus culture, the social expectation and demand for education, teaching facilities and conditions, and so on. Teaching environment on the teaching subject, teaching process and teaching results have a direct impact [2]. Good, harmonious teaching environment to make the teaching body in a pleasant atmosphere to work and study motivates them more, and through this a positive incentive effect on the teaching process and results. At the same time, the teaching environment in a certain extent is affected by the corresponding feedback.

Teaching main body composed of teachers and students two elements. Play of the role of teachers, on their own, depends on the teacher's own knowledge level, cognitive level, professional ethics, teaching methods, teaching strategy and the personality charm. One of students as the main teaching two plays an decisive role in teaching process and results [2]. And the development of this effect depends on the student's own some elements, including students' emotional factors, such as personality, learning motivation, interest, self-confidence, anxiety and effort degree, and non-intelligence factors (including its accept the education level and type, learning methods and strategies, students' personality traits and learning experience, and other relevant factors. The two elements of teaching main body interaction and influence of the teaching process and the result play an important role.

\section{English interactive teaching principle}

The subjectivity of the multi-dimensional interactive objects. Multi-dimensional interactive teaching aims to cultivate and develop the students' subjectivity, so more emphasis on heuristic education, optimizing the knowledge structure and emphasis on equality of opportunity, care about students' all-round development and the development of the individual [1]. Through inspiration, guides the student to the inner spiritual needs, to help students from the main body consciousness, body, ability and the main body personality, maximize stimulate students learning enthusiasm, make them learn to study, thinking and research, training them as an independent, active, creative understanding and practice of social main body.

Generative multi-dimensional interactive content. Multi-dimensional interactive teaching real, natural, pursuit of teaching teachers should timely capture those unpredictable factors of teaching and teaching situation, use can be generated by the resources to carry out the teaching, the teaching process is not only the book knowledge transfer and accept, but the book knowledge, students' original knowledge, teachers' knowledge "sold" to the classroom in the resonator, after collide with each other, between the knowledge fusion, correction, the growth and development, thus internalized into the system and the cognitive structure of the students' emotion [3].

Multidimensional interaction of interactivity. Multi-dimensional interactive teaching pay attention to the multi-dimensional interactive information, namely information incomplete, accepting, understanding, and processing is a teacher to the student or the student to the student the one, the influence of linear, but between teachers and students, between living knowledge, emotion, meaning and line of the two-way interaction process [3]. Here is the information it also includes interest, not just knowledge as well as emotional elements, etc. The role of teacher is reflected in the choice of teaching information, processing and "activate", guides the student to participate in learning activities to shape a "text" of teaching with the text dialogue, understanding, and of the spirit of sharing, promote the students' self construction and independent development, formed a joint exploration, teaching is learning.

Teaching process is based on discipline curriculum and syllabus, in a certain teaching mode, to achieve the teaching goal of the established, through the teachers and students of teaching and learning activities together, make the students master the system of cultural science knowledge and basic professional skills, the development of students' physical and psychological quality and social culture quality process [4]. Teaching process which includes teaching content, teaching objectives, teaching means, teaching methods and strategies such as elements, also includes the teaching main body in teaching environment of various cognitive activities. Whether the teaching process in the 
system integrated environment and teaching main body, and directly influence the teaching result. Explicit teaching process in school buildings or teaching base, in the teaching main body directly or indirectly, through a series of teaching activities and means, such as classroom teaching, internship base, or the second classroom learning, etc.).Implicit in teaching process teaching integrated environment, students under the indirect guidance or lack of teachers, through self-study or exposed to complete. Teaching process due to the influence of various factors, unity is complex and multifaceted.

\section{Strategy research of English interactive teaching}

Unlike traditional one-way transfer of knowledge teaching, multi-dimensional interactive teaching emphasizes two-way communication and exchanges between teachers and students, between teachers and students answers "teaching community". , and lots of large English classes, students' English level is uneven, so in the process of the implementation of the multi-dimensional interactive teaching teachers to do carefully designed multidimensional interaction problems before class, class reasonable arrangement of teaching procedures, makes every effort to realize the cooperative learning, students and teachers so as to achieve good teaching effect [4].

Carefully designed multidimensional interaction problem. Multi-dimensional interactive teaching to activate thinking problem, cause the multidimensional interaction. When teachers set the multidimensional interaction problems, should be based on the social reality, and combining with the teaching objectives and teaching tasks, the development and utilization of student life experience to determine the topic of discussion. The selected topic should be able to stimulate students' interest, and give full consideration to the students' knowledge structure, life experience, physical and mental characteristics and understanding ability, making the problem is challenging and incentive, promote students to active thinking [4]. Design problems as the main line, through the mutual communication between teachers and students, mutual influence, mutual inspiration and motivation between students and students, realize the multidimensional interaction, propagate the multi-dimensional interaction between teachers and students, and promote the students' construction of knowledge structure, so as to cultivate students' innovative thinking ability.

Reasonable arrangement of teaching procedures. Teacher in the interactive teaching create a good learning environment, so that the students can "move" rise. In the teaching process, teachers should reasonable arrangement of multi-dimensional interactive teaching steps, including teaching preparation before class, teaching practice in class and after class teaching further.

First, the teacher wants to design a good classroom knowledge related topics, elaborate courseware, and prepare teaching materials and documents, to the full spirit and positive attitude to face the students [5]. At the same time the teacher wants to decorate in the class, students' positive data access to lay the foundation for further discussion. Second, classroom questioning, discussion, debate and so on are all multi-dimensional interactive way of teaching, in the process of discussion, put forward different views to the student, the teacher must pay attention to listening, classified, guide students to think of questions to deep, also can consciously in the multi-dimensional interaction of classroom knowledge extended to extra-curricular, allow students to extrapolate, get twice the result with half the effort. Finally, the summary of this lesson after class and renewal, as well as help improve the quality of the next class and development of the teachers can build a multi-dimensional interactive platform between teachers and students in a number of ways, on a summary of classroom, unbridling for student's actual problem.

Strive to implement cooperative learning. Cooperative learning is a kind of in the form of group and team organization strategy of student learning, emphasizes the learners' creativity, autonomy and multi-dimensional interactive, advocate the teaching content activation for different tasks assigned to each group and collaboration between team members, sharing information and resources, common tasks [5]. In the multi-dimensional interaction of teaching, the harmony of students and teachers, and continuously strengthen partnership between each other. In the multi-dimensional interaction, share each other's understanding of point of view, and then form new thinking and understanding, not only save the knowledge in the cooperation, and create knowledge. 
The classroom teaching and learning interaction. Constructivism thinks that learning is a proactive behavior, by the learners themselves from own information to construct their own knowledge. So successful foreign language classroom teaching should take students as the center, to carry out a variety of teaching activities. On the basis of fully understand the characteristics of students, pay attention to, reflect and meet the needs of students, inspire the students' enthusiasm and initiative to participate in classroom teaching activities, through a lot of practice, cultivating and improving students' comprehensive language application ability [6]. Attracted the active participation of students, inspire students' thinking, through interaction to promote students' knowledge and thinking structure of change; Using interactive teaching methods, in the process of interaction and thinking, emphasizes the development of rich and colorful, multi-angle teaching activity, to ensure that students' learning initiative and creativity.

Based on constructivist classroom teaching, the teacher is not only the carrier of language knowledge and teaches, more to the organizers, managers, encourage, partners and other identity for the students to create relaxed and harmonious class atmosphere [5]. The teacher in the students fully understand the situation and interest, on the basis of targeted to prepare every lesson plan, organization participation high class activities, at any time to guide students to think, understand and apply the acquired knowledge, through the students' reflection log and online communication, timely adjust the class arrangement, use a variety of language rhythm, expression, and writing, imparting professional knowledge, good at discovering students' specialty, points out the shortage of students in time, into the students' activities, create the opportunity to develop the students' ability of autonomous learning.

Online learning, autonomous learning and teachers' guidance. Points of autonomic learning under the network environment of the two cases, one is a teacher to the network classroom instruction and supervision of students in the completion of the provisions of the teaching task, and according to each student's learning practice, give a face to face directly or tutorial, can also according to students' autonomous learning progress, timely detection and evaluation of student learning; The other is a teacher learning tasks, by the students themselves according to their own time, interest in content and plans, teachers can record tracking supervision through the network [3]. In recent years of teaching practice, we found that in the initial stage of network learning, students because of curious and fresh, can be completed on schedule network autonomous learning, but with the passage of time, students' lack of perseverance, self management ability is insufficient, has quite part of students cannot be unluckily to complete the learning task [6]. And leave the direct supervision of the teacher, the students' autonomous learning is more difficult to secure. Therefore, teachers should strengthen the guidance of network autonomous learning, help students to cultivate the ability of autonomous learning.

The second classroom + elective courses, teachers' guidance. Language ability is a long-term accumulation, the process of osmosis, limited only by the classroom teaching and practice it is difficult to achieve a goal. Constructivism theory is the core of: students are self control of knowledge construction. The central task of the teaching practice is to help students improve their cognitive abilities. To achieve this goal, educators should provide a good environment for the students, help them independently or collectively create their own opinions. So in order to ensure to improve the students' English level and skills, should carry out rich and colorful after-class learning activities. Extracurricular English learning can create more opportunities for language usage scenarios and use; Can increase language learners understanding of English national culture and so on various aspects, to cultivate the learner's independent thinking ability [6]. That can make learners realize the real value of English as a communication means, to improve their learning motivation, enhance learning confidence. Therefore, to guide and help students to take an active part in learning activities, as a useful supplement of classroom teaching. At the same time, in participating in extracurricular activities, students according to their own requirements actively decided to study the content and form, responsible for their own learning, don't rely solely on teaching management and methods provider's teacher, and also cultivate their ability of autonomous learning. 


\section{Summary}

University education objects of study from the simple pursuit of entrance and pass the exam to enhance vocational skills and professional development of diversified demand change. These requirements and changes make college English teaching is facing the challenges of the reform and development. Multi-dimensional interactive teaching method is kinds of democracy, freedom, equality, open teaching. Teachers in the teaching activities are the guide and participants, supporters and partners. By creating problem situation, stimulate students' interest in exploring, and in the process of multi-dimensional interactive multidimensional interaction between teachers and students and teachers, to learn creatively, and thus get vivid, lively, active development, can yet be regarded as one of teaching college English and other effective methods of teaching.

\section{References}

[1] W.Sh. Yuan, College English curriculum requirements based on constructivism of science education idea, Foreign education research, 2012, vol.6, pp.13-16.

[2] W.T. Dong, College English teaching of the network age, 2010, vol.10, pp.50-54.

[3] Ch.T. Xi, Multi-dimensional perspective of university teaching, China social sciences press, 2012.vol.2, pp.62-66.

[4] Y.Y. Huang, Multidimensional interactive college English teaching model to explore, Journal of Hunan agricultural university, 2007, vol.8, pp.11-14.

[5] R.M. Xue and Zh.Q. Luo, Multidimensional interactive college English teaching and research, Foreign language teaching and research, 2012, vol.8, pp.21-25.

[6] S.M. Yang, Current situation analysis and exploration of college English, Foreign language education, 2010, vol.3, pp.54-57. 